\title{
Estruturas concessivas intensivas no espanhol falado: um olhar discursivo-funcional
}

\author{
Intensive concessive structures in spoken Spanish: a \\ functional discourse point of view
}

Talita Storti GARCIA ${ }^{1}$

Camila Rodrigues de AMORIM²

\begin{abstract}
RESUMO: Estudam-se, neste artigo, as construções concessivas no espanhol peninsular falado introduzidas pela locução conjuncional por mucho que à luz da teoria da Gramática Discursivo-Funcional (HENGEVELD; MACKENZIE, 2008) a fim de investigar em que nível e camada propostos por esse modelo teórico essas orações atuam. Como universo de investigação, analisam-se inquéritos do Projeto PRESEEA (Proyecto para el Estudio Sociolingüístico del Español de España y de América) de acordo com os seguintes fatores: níveis e camadas de atuação, tempos e modos verbais das orações envolvidas, ordenação e acidentes prosódicos. Os resultados revelam que as orações prefaciadas por tais estruturas podem atuar na camada dos Atos Discursivos, quando constituem função retórica, ou ainda na camada Conteúdo Proposicional, quando constituem função semântica. O uso recorrente de novas construções na língua para expressar noções semânticas como a concessividade, como é o caso de Por mucho [N] que [N/pron] Vsubj (ROSÁRIO, 2014), pode ser explicado pelo fato de que as necessidades comunicativas levam os falantes a serem específicos, o que se reflete no processo da codificação.
\end{abstract}

PALAVRAS-CHAVE: Concessão. Língua Espanhola. Gramática Discursivo-Funcional

ABSTRACT: In this article, we study the concessive constructions in peninsular spoken Spanish introduced by conjunctive locution, por mucho que in the light of Functional Discourse Grammar theory (HENGEVELD; MACKENZIE, 2008). It is intended to investigate in which level and layer proposed by this theory these constructions act. As investigation universe, we analyze surveys from PRESEEA Project according to the following criteria: levels and layers of acting, verbal tenses and moods of the clauses, ordering and prosodic marks. The results show that the clauses prefaced by such structures can act in the layer of the Discursive Acts, as a rhetorical function, or even in the Propositional Content layer as a semantic function. The recurrent use of new constructions in the language to express semantic notions such as concessivity, as in the

\footnotetext{
1 Talita Storti Garcia é graduada em Letras com habilitação em espanhol, mestre e doutora em Estudos Linguísticos. Atua como professora Assistente Doutora da UNESP, campus de São José do Rio Preto, onde ministra aulas na Graduação e na Pós-Graduação. Dedica-se à descrição do português e do espanhol à luz do funcionalismo.

${ }^{2}$ Camila Rodrigues de Amorim é graduada em Letras com habilitação em espanhol pela UNESP, campus de São José do Rio Preto, onde atualmente cursa Mestrado em Estudos Linguísticos. Dedica-se, atualmente, à investigação das estruturas concessivo-condicionais no espanhol com base no funcionalismo.
} 
case of Por mucho [N] que [N/pron] Vsubj (ROSARIO, 2014), can be explained by the fact that communicative needs lead the speakers to be specific through grammatical coding.

KEYWORDS: Concession. Spanish Language. Functional discourse grammar.

\section{Introdução}

Uma oração concessiva prototípica ou própria (FLAMENCO GARCÍA, 1999), do ponto de vista tradicional, é aquela que, no âmbito estrutural, é introduzida por conjunções ou locuções conjuntivas do tipo aunque ou a pesar de que, no caso do espanhol (embora e apesar de que em português respectivamente). De acordo com a Nueva Gramática de la Real Academia Española (REAL ACADEMIA ESPAÑOLA, 2010) (doravante NGLE), o período concessivo introduz uma situação de contraexpectativa, ou seja, uma condição ineficaz, que não altera a realização do indicado na oração principal.

O sentido concessivo pode, no entanto, ocorrer também por meio de estruturas constituídas pela preposição por de origem causal, seguida de variantes como "más, muy ou mucho que", podendo introduzir subordinadas com subjuntivo de valor hipotético, ou conteúdos factuais com indicativo, conforme afirma Flamenco García (1999). Esse tipo de nexo, conforme Rosário (2014) oferece um matiz intensivo às construções concessivas, pois caracteriza uma intenção do falante de ser mais expressivo e específico, o que se concretiza por meio da materialização linguística. O falante, por exemplo, escolhe dizer "por mais que você insista que eu fique eu viajarei" ao invés de "embora você insista, eu viajarei", pois tem intenção de ressaltar a informação pragmática de que o fato de o indivíduo "muito" insistir, não é suficiente para a não ocorrência do evento da oração principal, no caso viajar.

Defendemos aqui a hipótese de que há uma diferença semânticopragmática entre as diferentes conjunções que assinalam a relação concessiva. Essa diferença está relacionada aos níveis e camadas propostos pela teoria da Gramática Discursivo-Funcional, já que, segundo Crevels (1998), o uso de diferentes conjunções para expressar o mesmo tipo de relação adverbial em 
determinada língua é atribuído à existência de níveis semânticos distintos de distribuição e de classificação das orações.

Como universo de nossa pesquisa, foi utilizado o corpus do projeto PRESEEA (Proyecto para el Estudio Sociolingüístico del Español de España y de América) - disponível na página da web: http://preseea.linguas.net. Analisamos os inquéritos coletados nas cidades de Alcalá de Henares, Madrid, Granada e Valência, situadas na Espanha. Buscamos respaldo teórico nos compêndios normativos, descritivos e funcionalistas para estudar a locução conjuntiva por mucho que, conforme ilustra a ocorrência a seguir:

(1) I: ese... ese es otro problema / los ... los nietos son maravillosos / e:I cariño que se tiene a los nietos / es superior al que se tiene a los hijos aun por mucho que se les quiera a los hijos $(3, \mathrm{H}-\mathrm{AH}, 3)^{34}$

Este artigo se organiza, portanto, do seguinte modo: na Seção (1) fizemos uma introdução à Gramática Discursivo-Funcional, que guiou nossa análise sobre as orações concessivas; na Seção (2) apresentamos as principais considerações sobre as construções introduzidas por por mucho que; na Seção (3) apresentamos algumas questões relacionadas ao corpus PRESEEA utilizado para a realização da análise dos dados, que por sua vez está apresentada na Seção (4), em que é feita a análise de cada fator investigado; e, por fim, nas Considerações Finais apresentamos um panorama geral de todos os fatores analisados.

\section{A Gramática Discursivo-Funcional: algumas considerações teóricas}

A teoria da Gramática Discursivo-Funcional tem como objetivo explicar os fenômenos morfossintáticos e fonológicos codificados em uma língua, e considera que esses fenômenos podem corresponder a aspectos pragmáticos e

\footnotetext{
${ }^{3}$ As indicações indicam respectivamente: o informante, o sexo do informante, o local em que foi realizada a pesquisa (Alcalá de Henares, no caso) e o número da entrevista correspondente ao trecho citado.

${ }^{4}$ I: este...este é outro problema / os... os netos são maravilhosos / o: carinho que se tem aos netos / é superior ao carinho que se tem aos filhos ainda por mais que amemos os filhos.
} 
semânticos presentes na formulação, ou acontecer de forma arbitrária na codificação.

Por possuir um modelo de arquitetura descendente da linguagem, a GDF está estruturada em termos de quatro componentes: o Componente Conceitual, ideal para o desenvolvimento da intenção comunicativa; o Componente Contextual que traz consigo o conteúdo e a forma discursiva, além do contexto real de comunicação, e as relações sociais dos interlocutores e o Componente de Saída, responsável pela geração das expressões acústicas ou escritas. Esses três componentes interagem com o Componente Gramatical, através das operações de formulação e de codificação, conforme se observa na figura a seguir:

A Figura (1) representa a integração entre os componentes acima explicados:

Figura 1 - A GDF como parte de uma teoria mais ampla da interação verbal

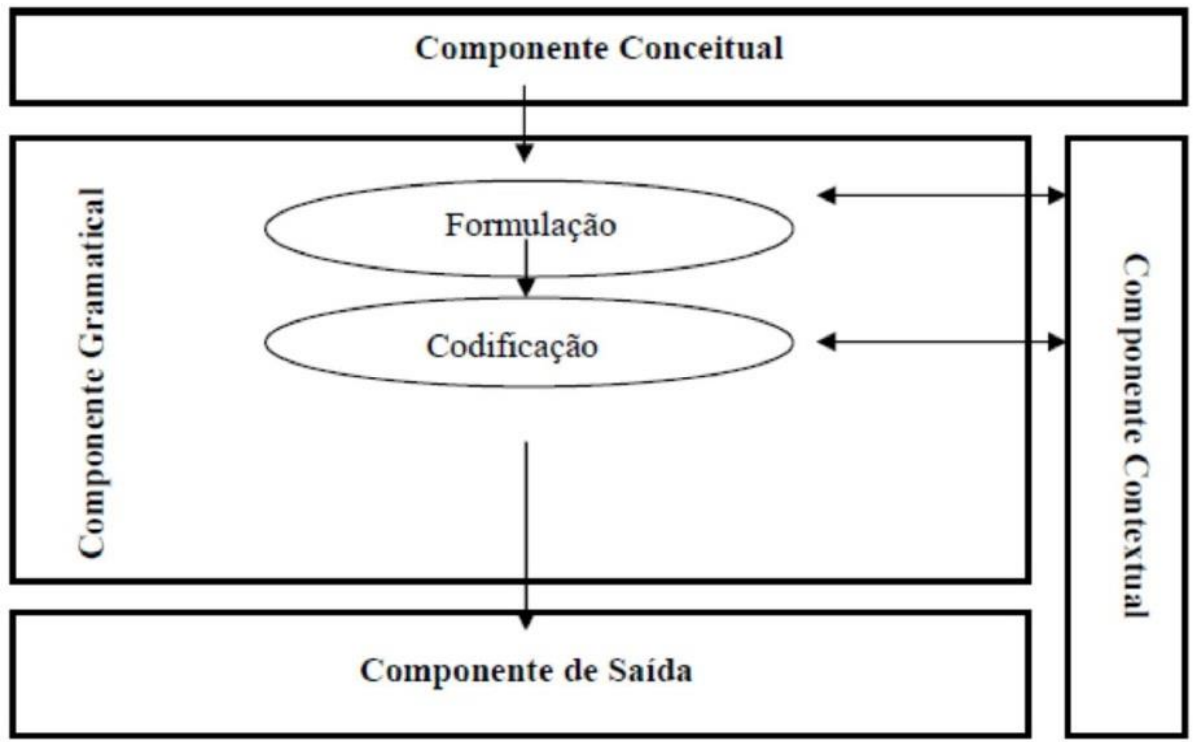

Fonte: Hengeveld e Mackenzie (2008, p. 6).

Cada um dos níveis de representação distinguidos dentro do Componente Gramatica/ tem em comum o fato de estarem organizados hierarquicamente em camadas. O Nível Interpessoal é o que se relaciona aos aspectos pragmáticos da interação comunicativa, ou seja, se relaciona aos aspectos formais da unidade linguística que refletem o papel do falante e do ouvinte na interação, e esse papel 
é analisado em termos de funções pragmáticas - modo pelo qual o falante estrutura a mensagem tendo em vista as expectativas do seu ouvinte - e retóricas - modo pelo qual os componentes do discurso são ordenados pelo falante a fim de atingir seu propósito discursivo.

As camadas do Nível Interpessoal são: Movimento (M), Atos Discursivos (A) e Conteúdo Comunicado (C).

- Camada do Movimento (M): O movimento (M) é a maior unidade de interação relevante para a análise gramatical. De acordo com Hengeveld e Mackenzie (2008), o movimento pode ser considerado como uma contribuição para a interação em desenvolvimento, e seu material linguístico pode variar de porções menores a longos trechos do discurso. Ademais, o movimento possui a forma de um ou mais Atos Discursivos, que podem se relacionar por equipolência ou dependência.

- Camada dos Atos Discursivos (A): Indica o que motivou o falante a proferir uma Ilocução. Um ato pode ser expressivo; interativo, quando trás material lexical cristalizado; ou ilocutivo, quando envolve conteúdo comunicado e uma ilocução lexical abstrata. Os Atos Discursivos podem manter entre si relações de equivalência ou dependência. As relações de dependência são entendidas como uma função retórica e podem ser: Motivação, Orientação, Correção e Concessão.

- Camada do Conteúdo Comunicado (C): O operador reportativo deve ser distinguido dos operadores evidenciais do Nível Representacional (Conteúdo Proposicional). Cada Conteúdo Comunicado tem um ou mais subatos, que são subordinados aos Atos Discursivos. O Conteúdo Comunicado contém o que os interlocutores desejam evocar na comunicação.

Hengeveld e Mackenzie (2008) apresentam a relação de dependência entre Atos, um Nuclear (principal) e outro Subsidiário (dependente), como função 
retórica de concessão, e isso pode constituir uma estratégia do falante para guiar o seu interlocutor e atingir seus objetivos conversacionais:

(2) The work was fairly easy, although it took me longer than expected. ${ }^{5}$ (HENGEVELD; MACKENZIE, 2008, p. 54)

Ressaltam Hengeveld e Mackenzie (2008, p. 55) que a ordenação entre o Ato Nuclear e o Subsidiário é um fator de extrema importância para a classificação das estruturas concessivas em camadas, pois, caso a ordem das orações apresentadas em (2) seja alterada, ou seja, caso a oração concessiva ocorra antes da oração principal, temos uma pista morfossintática de que a concessão não mais ocorre entre Atos Discursivos, mas sim entre Conteúdos Proposicionais, já no Nível Representacional, como função semântica.

(3) Although the work took longer than expected it was easy. ${ }^{6}$ (HENGEVELD; MACKENZIE, 2008, p. 55)

Os Conteúdos Proposicionais (p), unidades mais altas do Nível Representacional, são construtos mentais, ou seja, estão relacionados aos conhecimentos, crenças e desejos do falante. Enquanto os Conteúdos Comunicados (C) - pertencentes ao Nível Interpessoal - sempre são atribuídos ao falante, os Conteúdos Proposicionais ( $p$ ) podem ser atribuídos, sem nenhum problema, a outras pessoas que não sejam o falante, conforme se observa no exemplo a seguir:

(4) Jenny acreditava que/ esperava que/ foi para casa porque ta/vez sua mãe fosse visita-la. (HENGEVELD; MACKENZIE, 2012, p. 55).

O advérbio talvez revela o caráter proposicional da parte em itálico, referente ao indivíduo Jenny introduzido na oração principal.

\footnotetext{
${ }^{5} \mathrm{O}$ trabalho foi razoavelmente fácil, embora tenha levado mais tempo que o esperado.

${ }^{6}$ Embora o trabalho levou mais tempo que o esperado, foi fácil.
} 
As demais camadas do Nível Representacional são: Episódio, Estados-deCoisas e Propriedade Configuracional. Todas as camadas desse nível podem ser resumidas como segue:

- Conteúdo Proposicional (p): Quando diz respeito a conhecimento ou crenças sobre o mundo, pode ser factual, mas quando corresponde a desejos ou expectativas sobre um mundo imaginário, pode ser não factual.

- Episódio (ep): Conjunto de estado de coisas que carregam unidade ou continuidade de tempo (t), localização (I) e indivíduos, e, por isso são tematicamente coerentes.

- Estado-de-Coisas (e): Combina unidades semânticas que não estabelecem relações de hierarquia entre si.

- Propriedades Configuracionais (f): Utilizam categorias semânticas que não estabelecem uma relação de hierarquia entre si.

Por fim, tem-se ainda o Nível Morfossintático e o Nível Fonológico, que codificam as distinções interpessoais e representacionais. A GDF não diferencia o nível sintático e o nível morfológico de análise, por isso, aceita a denominação Morfossintática para referir-se ao nível que cuida dos aspectos estruturais de uma unidade linguística. No Nível Fonológico, por sua vez, são fornecidas as indicações que o componente de saída converte em resultado sonoro.

Após introduzir brevemente o modelo teórico que embasa a presente pesquisa, a Gramática Discursivo-Funcional, de Hengeveld e Mackenzie (2008), trataremos dos conceitos de concessividade, que são indispensáveis para a compreensão das questões referentes à construção por mucho que.

\section{O conceito de concessão e a construção intensiva por mucho que}


Do ponto de vista de Rosário (2014), as construções concessivas por serem pouco gramaticalizadas, ainda estão em processo de mudança e de estabilização no sistema linguístico. Essa instabilidade, por sua vez, faz com que as suas propriedades semântico-pragmáticas e funcionais ainda estejam se delineando na língua portuguesa. Por essa razão, a construção concessiva intensiva prefaciada por por mucho que, na visão do autor, é uma mesoconstrução pois pode ser esquematizada como Por mucho [N] que [N/pron] $V s u b j$, ou seja, que pode ocorrer em formas nem sempre rígidas, pois apresenta certa variabilidade sintagmática, como no caso das estruturas entre colchetes.

A mudança linguística ocorre, pois, para dar conta de novas necessidades comunicativas oriundas da dinâmica social. Essa seria uma das motivações para o surgimento de novas construções na língua, como é o caso de Por mucho [N] que [N/pron] Vsubj (adaptado de ROSÁRIO, 2014). As necessidades comunicativas levam os falantes a serem cada vez mais específicos, o que se revela no processo de codificação gramatical.

Do ponto de vista formal, Flamenco García (1999) afirma que a construção por mucho se usa somente com subjuntivo, fazendo referência geralmente a situações hipotéticas. Em alguns casos, o subjuntivo pode expressar também conteúdos factuais, como se observa no diálogo a seguir:

(5) A: Ten cuidado con este. Sabe muchas cosas.

B: Pues por mucho que sepa, a mí no me va a acomplejar. (FLAMENCO GARCÍA, 1999, p. 3837).

Haspelmath e König (1998) classificam as construções do tipo por mucho que no rol das condicionais concessivas universais (Universal Concessive Conditiona/s), pois, segundo os autores, expressam circunstâncias de caráter generalizador. As condicionais concessivas, de acordo com esses autores, apresentam, a partir de uma relação lógico-semântica, estatuto híbrido, pois, para eles, combinam características tanto das concessivas quanto das condicionais. 
Com as concessivas, as condicionais concessivas compartilham a característica de descreverem eventos que contrariam a expectativa do ouvinte de acordo com o princípio da regularidade, ou seja, elas negam, na oração principal, o que seria 'normal' ocorrer no mundo real (KÖNIG, 1994; DANCYGIER, 1988, 1998; SWEETSER, 1990), e o resultado expresso na oração principal independe da circunstância descrita na oração subordinada.

Com as condicionais, por sua vez, as construções condicionais concessivas compartilham a propriedade da hipoteticidade, isto é, não descrevem fatos, mas sim, expressam conteúdos em termos de suposição, de caráter hipotético, nãofactuais. Por apresentarem um conteúdo hipotético na oração subordinada e um conteúdo factual na oração principal, as construções condicionais concessivas são consideradas semifactuais, conforme atestam Haspelmath e König (1998, p. 567).

No arcabouço teórico da Gramática Discursivo-Funcional, no entanto, a formulação da expressão linguística parte da intenção comunicativa do falante, ou seja, considera-se que o falante não tem dúvida sobre o que deseja expressar, o que torna as questões híbridas bastante contestáveis.

\section{Metodologia}

O córpus adotado para esta pesquisa é composto por amostras extraídas do Projeto PRESEEA (Proyecto para el Estudio Sociolingüístico del Español de España y de América), coordenado pelo professor Francisco Moreno, da Universidade de Alcalá de Henares, Espanha. O Projeto também disponibiliza amostras de língua falada de cidades espanholas e latino-americanas na seguinte página da web: preseea.linguas.net. Na seção (4), onde se encontra nosso levantamento de dados da pesquisa, pode-se perceber, junto aos excertos do corpus, as indicações das seguintes variáveis sociais: 0 sexo (Masculino/ Feminino), a idade e o grau de instrução dos entrevistados.

Considerando a variedade de "idade", os participantes têm, em geral, no mínimo 20 anos e são divididos em três grupos: os que têm de 20 a 34 anos, de 
35 a 54 anos e, por último, de 55 anos em diante. Sobre o grau de instrução dos entrevistados, são adotadas as etapas de escolarização referentes ao ensino na Espanha: enseñanza primaria, secundaria ou superior.

É importante ressaltar que esta pesquisa não segue uma perspectiva sociolinguística, por isso não relaciona os fatores de análise com os fatores socialmente controlados pelo PRESEEA tais como idade, sexo, escolaridade, etc. O foco desta investigação é a descrição do espanhol peninsular falado considerando os aspectos sintáticos, semânticos e pragmáticos envolvidos na construção da concessão e, de acordo com a perspectiva funcionalista, as amostras do espanhol falado suprem as expectativas de uma análise da língua em contextos reais de comunicação, pois permite que se observem as intenções de quem fala, onde, porque e para quem fala.

Como dito, cada ocorrência apresenta uma identificação ao final, como $(17, M-A H, 5)$ por exemplo, que corresponde, respectivamente, ao número do informante no corpus (17), seu sexo (F para feminino e M para Masculino), ao lugar onde foi realizada a pesquisa (AH - Alcalá de Henares) e, por fim, ao número da entrevista (5). Para o presente estudo, utilizamos um total de 16 ocorrências coletadas dos inquéritos das cidades de Alcalá de Henares, Granada, Madrid e Valência, localizadas na Espanha. Os inquéritos da cidade de Alcalá são compostos por três volumes (CDs) com 18 entrevistas cada e mais de 45 minutos de gravação por inquérito. Já as entrevistas das outras cidades foram retiradas da página da web, que não dispunha as gravações de áudio completas. Utilizamos, portanto, apenas a transcrição das entrevistas das cidades de Granada, Madri e Valência para a análise dos dados. Levantamos um total de 11 ocorrências de estruturas concessivas introduzidas por por mucho que.

Todos os arquivos apresentam transcrição e gravação, que foram previamente elaboradas e organizadas pela equipe de professores responsáveis pelo PRESEEA, o que nos permitiu ouvir e compreender os contextos de fala de todos os inquéritos.

A fim de alcançar os objetivos propostos por esta pesquisa, foram utilizados cinco fatores de análise previamente estabelecidos: 
1) Níveis e camadas de atuação da concessão;

2) Modo verbal da oração concessiva;

3) Ordenação da oração concessiva com relação à principal: anteposta ou posposta;

4) Acidentes prosódicos (pausas, contorno prosódico, mudança de tessitura ou de altura) nas fronteiras da oração concessiva.

O primeiro fator de análise pretende mostrar em quais Níveis e Camadas, propostos pela GDF, se dá a relação de concessão introduzida por por mucho que: no Nível Interpessoal ou Representacional. As camadas postuladas pelo modelo da GDF são: Movimento, Ato Discursivo e Conteúdo Comunicado, que pertencem ao Nível Interpessoal; Conteúdo Proposicional, Episódio, Estados de Coisas e Propriedade Configuracional, que pertencem ao Nível Representacional.

O tempo e o modo verbal da oração concessiva introduzida por por mucho que é o segundo fator de análise. Ao observar o tempo e o modo dessa oração, é inevitável olhar para a correlação verbal existente entre a subordinada e a principal, ou seja, as duas orações envolvidas.

O terceiro fator se refere à posição da oração subordinada com relação à oração principal: anteposta ou posposta, tomando-se o verbo da oração principal como ponto de referência. A posição é conceituada, de acordo com a perspectiva funcional, como um resultado das intenções comunicativas do falante, ou seja, é o resultado da autonomia da pragmática e da semântica sobre a sintaxe.

Por fim, o quarto fator diz respeito à ocorrência de qualquer tipo de acidente prosódico nas fronteiras das orações concessivas, como, por exemplo, pausas longas ou curtas, mudança de tessitura, aumento da velocidade da fala, contorno entonacional próprio ou qualquer tipo de mudança prosódica com relação ao contexto anterior ou posterior. Na Seção a seguir trataremos concomitantemente dos Níveis e das camadas de atuação da concessão.

\section{Níveis e camadas de atuação da concessão}


Os resultados desta pesquisa revelam que as estruturas concessivas prefaciadas pela variante por mucho que-dentre outras variantes como más ou muy - no espanhol peninsular falado foram mais recorrentes. Encontramos cinco ocorrências dessas estruturas atuando no Nível Representacional, conforme se observa a seguir de (6) a (10):

(6) cuando de verdad estás/ plenamente convencido de que quieres dejar de fumar/ entonces por mucho que te digan los demás// o "mira qué es malo fumar/ que no lo hagas/ que es por tu salud/ que"// yo creo que/ cuanto más te dicen// "no hagas esto"// mm más tienes ganas de hacerlo $(2, M-G R A, 2)$

(7) yo creo que por mucho que le dijese y por mucho que le aconsejase / sería bastante difícil que dejase de fumar mi padre <risas $>(1, \mathrm{H}-$ VALE, 3)

(8) aquellos años tan ... tan extraordinarios que son los años sesenta / y que / no es ... / no es un pegote mío / que yo recuerdo que cuando ... cuando estábamos en los años sesenta / terminando los años sesenta / yo dije // por mucho que cambie este país // estos años ya no volverán $(3, \mathrm{H}-\mathrm{AH}, 3)$

(9) yo creo que que lo tenemos difícil por la situación por la situación en la que vivi en la situación en la que vivimos / porque // económica pues ... hemos: pasado unos momen... ahora también ¿no? / porque dicen que: ... / la situación económica está mejorando // pero: ... pero: realmente: ... / por mucho que mejore / no hay no hay trabajo / no se encuentra trabajo entonces / (1, M-VALE, 3$)$ 
(10) I: que yo no lo admito como bueno entonces tú por mucho que me lo pidas / yo creo que no lo haría no lo sé / es que/ no lo sé / yo pienso eso $(1, \mathrm{M}-\mathrm{AH}, 3)$

É interessante observar nessas orações a presença de expressões que demonstram crenças ou opiniões, como é o caso de yo creo que em (6), ou seja, construtos mentais que passam pelo crivo do falante, o que configura, na GDF, Conteúdos Proposicionais. Nesses casos, portanto, a relação concessiva introduzida por por mucho que se dá entre Conteúdos Proposicionais, camada mais alta do nível representacional.

A relação de concessão, nesse contexto, faz referência a percepções, avaliações e/ou crenças do falante e, por isso, envolve um alto grau de abstração. Em (6) o informante assegura que por mais que as pessoas digam "pare de fumar", mais ele tem vontade de seguir com esse hábito; o que se apresenta na oração principal refuta o conteúdo da oração subordinada. A ocorrência (7) também representa a relação concessiva no domínio do conteúdo, pois o falante afirma que por mais que aconselhasse seu pai, ele dificilmente deixaria de fumar. Em (8) o falante discorre sobre os inesquecíveis anos 60, e assegura que mesmo que seu país tenha mudado (melhorado), aqueles anos tão saudosos jamais voltariam. Em (9), a informante afirma que por mais que a situação econômica de seu país esteja melhorando, não há trabalho. Em (10), por fim, o entrevistador pede opinião da informante sobre eutanásia, que responde: por mais que alguém peça, eu (acredito que) não o faria.

As demais ocorrências introduzidas por por mucho que observadas no córpus, diferentemente desse caso, não mais se relacionam a crenças e construtos mentais mas sim à circunstância da enunciação, conforme se observa de (11) a (16).

(11) E: $\quad$ Y volviendo a la enseñanza/ $m m$ los jóvenes de ahora ccómo los ves tú respecto a la disciplina?// ¿ha cambiado mucho la relación profesor alumno desde que empezaste hasta ahora? 
I: [...] es muy difícil tener alumnos en un aula que no quieren estar ahí/ ¿eh? entonces eso es una realidad por mucho que los políticos/ el Ministerio/ la Junta se pretenda que los alumnos/ mm salgan con unos estudios/ si esos alumnos no tienen voluntad en absoluto/ (3, M - GRA, 3)

(12) claro que hay asignaturas que no te vas a convertir en un experto en notación o/ o en según qué cosas ¿no? ee/ en materia no te vas a convertir en un experto en un año ¿no? por mucho que trabajes ¿no? $(3, M-G R A, 1)$

(13) I: yo creo que esta generación o estas generaciones están perdi(d)as// pero a largo plazo tú si puedes ir/ hacerle a la gente que esté de otra manera// y mientras tanto/ pues yo si tuviera hijos/ apáticos/ por desgracia en esta época// pues yo sé que está mal porque va contra mis principios/ pero usaría la prohibición antes que estén todos los días bebiendo esas cantidades de alcohol// aunque sé que prohibiéndoselo también sé yo que lo van a hacer/// pero por lo menos que entiendan que yo no estoy de acuerdo con mi consentimiento no/ hombre le explicaría por qué/ no lo que pasa es que/ explicárselo// es como jugar a la Game Boy// si obtienen/ les gusta y si no obtienen puntos no les gusta como lo que yo les estoy diciendo no les gusta no me van a hacer caso ni me van a escuchar// por mucho que a lo mejor fueran mis hijos y me quisieran/// entonces es muy muy difícil. (3, M-GRA, 2)

(14) E: ¿Cómo eran las fiestas// a las que asistía en aquella época?

I: Pues las recuerdo muy olorosas// y digo eso porque se celebraban en la plaza de abastos// ts// quizá fuera el único local cerra(d)o que había para celebrar las fiestas/// las primeras fiestas que yo recuerdo luego se... hubo otro lugar pero en fin aquellas las recuerdo muy olorosas porque aunque se lavaban los puestos/// por la noche/ a la 
hora de la verbena/ aquello/ olía a pesca(d)o/// por mucho que se quisiera limpiar y por mucho aqua que se baldeaba// $(3, \mathrm{H}-\mathrm{GRA}, 3)$

(15) I: ese... ese es otro problema / los ... los nietos son maravillosos / e:I cariño que se tiene a los nietos / es superior al que se tiene a los hijos aun por mucho que se les quiera a los hijos $(3, \mathrm{H}-\mathrm{AH}, 3)$

(16) I: y entonces fue: / para mí fue muy duro // pero vamos / a lo mejor tardaría un año: / o algo así en:/ // asimilar la situación /

$\mathrm{E}: \mathrm{hm}$

I: y: la verdad es que después / me alegro muchísimo

E: te alegras ¿no? de ver otras parejas y otras relaciones

I: muchísimo porque: yo:/ veo que mi madre está mejor mi padre está mejor y yo también estoy mejor porque no estoy viendo peleas constantemente

E: claro / seguro porque los niños terminan por percibirlo por mucho que sean discretos

I: no no yo: la verdad es que: / a largo plazo veo que es lo mejor que se podía haber hecho en ese momento / pero claro en ese momento tch además eres muy pequeño y entonces / sabes lo que está pasando pero no entiendes por qué / $(1, M-M A D R, 3)$

Em (11) a informante, que afirma ser professora, discorre sobre a atual relação professor/aluno nas escolas. A entrevistada assegura que por mais que os órgãos governamentais esperem que os alunos saiam das instituições de ensino com alguma formação, é muito difícil ter alunos em sala de aula que não querem de fato estar ali. A informante ressalta ainda que muitos desses alunos acabam atrapalhando o ambiente escolar.

Em (12), o falante afirma que não é possível se tornar um expert no trabalho em um ano, por mais que você se esforce. Em (13), a informante fala sobre o consumo de álcool por menores de idade, e assegura que proibir muitas 
vezes não é a saída, uma vez que os jovens o fazem de qualquer maneira. A informante acredita que se tentasse proibir seus filhos, eles não a escutariam, por mais que pudessem amá-la. Em (14), pois, o informante discorre sobre as festa de antigamente, e se lembra de um forte odor dos pescados. Ele afirma que, por mais que se tentasse limpar o lugar, aquilo estava sempre cheirando a peixe. Em (15) o informante afirma que o carinho que se tem aos netos é superior ao que se tem aos filhos, por mais que se amem os filhos. Essa ocorrência representa muito bem a função retórica concessão, pois o falante retoma o que tinha dito, como uma "correção" do Ato anterior. Ele tenta convencer seu ouvinte de que ama também seus filhos. Por fim, em (16) o informante discorre sobre a separação de seus pais quando ainda era criança, e afirma que fora muito difícil assimilar a situação naquela época, mas atualmente percebe que seus pais vivem mais felizes. O entrevistador, por sua vez, comenta que por mais que os pais sejam discretos, as crianças percebem quando os pais não estão bem ou brigando muito.

Em todos esses casos de oração concessiva, pode-se observar que o falante está, por meio da concessão, concedendo algo, ou seja, ponderando um conteúdo que se relaciona ao conteúdo apresentado na oração principal, imediatamente anterior. Vemos, aqui, uma clara estratégia comunicativa do falante para persuadir e convencer seu interlocutor.

Nos termos de GDF, ambas as orações envolvidas, principal e concessiva, atuam no domínio do Ato Discursivo no Nível Interpessoal. Trata-se, pois, de uma relação entre dois Atos Discursivos, um Nuclear (representado pela oração principal) e outro Subsidiário (representado pela oração concessiva). As relações entre dois Atos Discursivos, nesse arcabouço, se caracterizam por apresentarem a função de guiar, persuadir ou convencer o interlocutor a respeito de algo que é dito anteriormente (HENGEVELD; MACKENZIE, 2008), trata-se da função retórica concessão. Nesse caso, o falante, por meio da concessão, concede ao ouvinte a oportunidade reconhecer que talvez o primeiro Ato Discursivo não fosse por ele esperado ou adequado no momento da interação. 
Como podemos observar, em resumo, os dados revelam que as orações concessivas introduzidas por por mucho que no espanhol peninsular falado atuam em duas diferentes camadas e em dois Níveis distintos: na camada do Conteúdo Proposicional, no Nível Representacional, e na camada do Ato Discursivo, no Nível Interpessoal. Tivemos como resultado $55 \%$ das ocorrências atuando na camada do Ato Discursivo, e 45\% das ocorrências atuando na camada do Conteúdo Proposicional.

\section{Tempo e modo verbal da oração principal e da oração concessiva}

As características modo-temporais das construções concessivas são muito particulares. A alternância entre os modos indicativo e subjuntivo é permitida em orações introduzidas pelo nexo aunque, e outros, mas de acordo com as gramáticas tradicionais e até de cunho mais descritivista, essa alternância não ocorre com as orações prefaciadas por por mucho que. Tanto na Gramática de Matte Bon (1995) como na Gramática de la Real Academia Española (2010), ou ainda na de Bosque e Demonte (1999), essas construções ocorrem com verbos apenas do subjuntivo.

Esses autores vinculam a alternância de modo verbal à realidade ou irrealidade do que é expresso na oração concessiva: basicamente, quando o verbo aparece no indicativo, existe, de fato, um obstáculo para o cumprimento do que foi dito na oração principal e esse obstáculo é visto como real; o uso do verbo no subjuntivo, por sua vez, apresenta esse impedimento apenas como possível, não com real.

Matte Bon (1995) postula que a motivação para se utilizar o verbo no indicativo ou no subjuntivo é a informação contida na oração concessiva. Sendo assim, quando a informação veiculada pela oração concessiva é nova para o interlocutor, o verbo aparece no indicativo. Para o uso do subjuntivo, o conteúdo expresso na oração concessiva deve consistir em uma informação já conhecida dos participantes da interação. 
Em nosso córpus de pesquisa, de maneira geral, confirmamos a hipótese apresentada pelos compêndios gramaticais de que as orações introduzidas por por mucho que tendem a ocorrer com verbos no subjuntivo, por apresentarem caráter factual ou hipotético, pois em $100 \%$ das ocorrências os verbos da oração concessiva ocorrem nesse modo verbal.

Quanto à oração principal, na maioria dos casos (82\%), o verbo ocorre no indicativo, e em apenas duas ocorrências (18\%) ocorre perifrase verbal (cujo verbo principal se mantém no indicativo) tanto nos casos em que a relação concessiva se dá no domínio do Conteúdo Proposicional como no domínio do Ato Discursivo. Segue, portanto, dois quadros que ilustram as correlações verbais das nossas ocorrências, representando tempo e modo verbal das construções introduzidas por por mucho que:

Quadro 1 - Correlações verbais das orações na camada do Conteúdo Proposicional

\begin{tabular}{|l|l|}
\hline Função Semântica - Domínio do Conteúdo Proposicional \\
\hline Oração Principal & Oração concessiva \\
\hline $\begin{array}{l}\text { Modo Indicativo: más tienes ganas de } \\
\text { hacerlo }\end{array}$ & $\begin{array}{l}\text { Modo Subjuntivo: por mucho que te digan los } \\
\text { demás }\end{array}$ \\
\hline Modo Indicativo: estos años ya no volverán & $\begin{array}{l}\text { Modo Subjuntivo: por mucho que cambie este } \\
\text { país }\end{array}$ \\
\hline Modo Indicativo: no hay no hay trabajo & Modo Subjuntivo: por mucho que mejore \\
\hline Modo Indicativo: yo creo que no lo haría & Modo Subjuntivo: por mucho que me lo pidas \\
\hline $\begin{array}{l}\text { Modo Indicativo: sería bastante difícil que } \\
\text { dejase de fumar mi padre }\end{array}$ & $\begin{array}{l}\text { Modo Subjuntivo: yo creo que por mucho que } \\
\text { le dijese y por mucho que le aconsejase }\end{array}$ \\
\hline
\end{tabular}

Fonte: Os Autores. 
Quadro 2 - Correlações verbais das orações na camada do Ato Discursivo

\begin{tabular}{|l|l|}
\hline \multicolumn{2}{|c|}{ Função Retórica - Domínio dos Atos Discursivos } \\
\hline \multicolumn{1}{|c|}{ Oração Principal } & \multicolumn{1}{|c|}{ Oração concessiva } \\
\hline $\begin{array}{l}\text { Modo Indicativo: es muy difícil tener alumnos } \\
\text { en un aula que no quieren estar ahí }\end{array}$ & $\begin{array}{l}\text { Modo Subjuntivo: por mucho que los políticos/ } \\
\text { el Ministerio/ la Junta se pretenda que los } \\
\text { alumnos/ mm salgan con unos estudios }\end{array}$ \\
\hline Modo Indicativo: aquello/ olía a pesca(d)o/// & $\begin{array}{l}\text { Modo Subjuntivo e Indicativo: por mucho que } \\
\text { se quisiera limpiar y por mucho agua que se } \\
\text { baldeabal/ }\end{array}$ \\
\hline $\begin{array}{l}\text { Modo Indicativo: e:I cariño que se tiene a los } \\
\text { nietos / es superior al que se tiene a los hijos }\end{array}$ & $\begin{array}{l}\text { Modo Subjuntivo: por mucho que se les quiera } \\
\text { a los hijos }\end{array}$ \\
\hline $\begin{array}{l}\text { Modo Indicativo: los niños terminan por } \\
\text { percibirlo }\end{array}$ & $\begin{array}{l}\text { Modo Subjuntivo: por mucho que sean } \\
\text { discretos }\end{array}$ \\
\hline $\begin{array}{l}\text { Perífrase verbal (ir + infinitivo): no te vas a a } \\
\text { convertir en un experto en un año }\end{array}$ & Modo Subjuntivo: por mucho que trabajes \\
\hline $\begin{array}{l}\text { Perífrase verbal (ir + infinitivo): no me van a } \\
\text { hacer caso ni me van a escuchar }\end{array}$ & $\begin{array}{l}\text { Modo Subjuntivo: por mucho que a lo mejor } \\
\text { fueran mis hijos y me quisieran }\end{array}$ \\
\hline
\end{tabular}

Fonte: Os Autores.

\section{Posição da oração subordinada com relação à oração principal}

A GDF admite que a posição da oração subordinada com relação à principal não é aleatória, mas obedece a propósitos comunicativos. Para Hengeveld e Mackenzie (2008), como vimos, a concessão é uma função retórica, uma relação que ocorre quando o Ato Subsidiário, que carrega a concessão, se refere a um Ato Nuclear. Nesse caso, o falante deseja atingir seus objetivos conversacionais como o de persuadir, convencer ou guiar o seu ouvinte. Assim, a oração concessiva, que corresponde ao Ato Subsidiário de concessão, ocorrerá posposta ao Ato Nuclear, que corresponde à oração principal.

Neves (2000) e Flamenco García (1999), afirmam que as concessivas antepostas carregam informação já conhecida para o interlocutor e, por isso, tendem a ocupar posição tópica. A anteposição é uma forma de o locutor já "prevenir-se" contra as fortes objeções do interlocutor. Em outros termos, a anteposição tem a função de poupar a face do outro (MARGARIDO, 2010, p. 109). Trata-se, portanto, de uma espécie de proteção defensiva, que está justamente no cerne da concessividade. $\mathrm{Na}$ anteposição, traz-se para o discurso "o objetivo de antecipar-se a uma possível contra-argumentação" (GOUVÊA, 2002, p. 37, grifo nosso). 
Em nossos dados, observamos que as orações concessivas introduzidas pela construção por mucho que ocorrem predominantemente pospostas à oração principal, quando atuam na camada do Ato Discursivo e antepostas quando atuam na camada do Conteúdo Proposicional.

Para a Gramática Discursivo-Funcional, a posição da oração subordinada com relação à principal não é aleatória, mas obedece a propósitos comunicativos. Nestes casos, explicamos a posposição da oração concessiva com relação à principal devido à função da concessão, que é a de conceder algo com relação ao que foi mencionado no Ato Discursivo anterior. Como já mencionado, a concessão, nesse caso, constitui uma função retórica, por isso, a oração concessiva, que corresponde ao Ato Subsidiário de concessão, ocorrerá geralmente posposta ao Ato Nuclear, que corresponde à oração principal. Para finalizar a etapa de análise dos dados, passaremos a tratar dos acidentes prosódicos nas fronteiras da concessão.

\section{Acidentes Prosódicos}

De acordo com Crevels (1998), estudar os acidentes prosódicos nas fronteiras das orações concessivas auxilia na identificação do domínio ao qual pertence a concessão. Esses acidentes prosódicos dizem respeito a qualquer tipo de elemento que quebre a união entre a oração principal e a concessiva, pode ser representado por pausas longas ou curtas, mudança de tessitura, aumento da velocidade da fala, contorno entonacional próprio ou outra alteração prosódica que influencie no contexto.

Os sinais (/ ou // ou ///) utilizados na transcrição do Projeto PRESSEA, indicam pausas curtas, médias e longas, respectivamente. $O$ quadro a seguir resume os acidentes prosódicos nas fronteiras das construções concessivas das ocorrências enumeradas na seção 5.1: 
Quadro 3 - Resumo dos acidentes prosódicos nas fronteiras da construção concessiva

\begin{tabular}{|l|l|l|l|}
\hline & $\begin{array}{l}\text { Pausa breve (/) ou } \\
\text { ausência de pausa }\end{array}$ & $\begin{array}{l}\text { Pausa longa } \\
\text { (// ou //I) }\end{array}$ & $\begin{array}{l}\text { Presença de Atos } \\
\text { Interativos (ieh? ino?) }\end{array}$ \\
\hline $\begin{array}{l}\text { Nível } \\
\text { Representacional } \\
\text { por mucho que }\end{array}$ & $\begin{array}{l}\text { Ocorrência (7), (9), } \\
(10)\end{array}$ & $\begin{array}{l}\text { Ocorrência (6), } \\
(8)\end{array}$ & \\
\hline $\begin{array}{l}\text { Nivel Interpessoal } \\
\text { por mucho que }\end{array}$ & Ocorrência (15), (16) & $\begin{array}{l}\text { Ocorrência (13), } \\
(14)\end{array}$ & Ocorrência (11), (12) \\
\hline
\end{tabular}

Fonte: Os Autores.

Quanto à construção por mucho que, as pausas breves ou ausência destas ocorrem mais nas fronteiras das orações concessivas quando atuam no Nível Representacional, enquanto que as pausas mais longas e a presença dos Atos Interativos caracterizam a relação concessiva no Nível Interpessoal.

\section{Considerações Finais}

Tendo como base a teoria da Gramática Discursivo-Funcional, constatamos, de maneira geral, que as construções prefaciadas por mucho que podem constituir um afterthought (CHAFE, 1976 apud RODRIGUES; CAMPOS; GALEMBECK, 1999), em que o falante volta ao que acaba de dizer para reconsiderar ou pesar a posteriori o que foi dito. Nesse caso, na perspectiva da GDF, atuam no domínio dos Atos Discursivos como função retórica, em que o falante, volta ao conteúdo comunicado no Ato Nuclear para conceder algo e atingir seus propósitos comunicativos. Nossos dados mostram também que essas construções podem se dar, além desse primeiro caso, no domínio do Conteúdo Proposicional como função semântica, único tipo apresentado pelos compêndios normativos, em que o falante apresenta um possível obstáculo, mas que se constitui como insuficiente, para impedir a realização do que está proposto na oração principal.

No caso da relação modo-temporal das orações introduzidas por por mucho que, comprovamos que o modo subjuntivo é mais recorrente nessas 
construções. Quanto à posição, vimos que as concessivas prefaciadas por por mucho que tendem a aparecer pospostas à oração principal, no Nível Interpessoal, quando atuam no domínio de Ato e antepostas quando atuam no domínio do Conteúdo. Confirmamos também a importância da análise dos acidentes prosódicos nas fronteiras das orações, uma vez que as orações concessivas que atuam no Nível Interpessoal apresentam quebras prosódicas mais acentuadas em suas fronteiras.

O desejo do falante de ser mais expressivo faz com que a codificação gramatical incorpore outros elementos e crie novos arranjos que se manifestam no nível do discurso, como por exemplo, no caso de o falante escolher proferir por mucho que me pidas, no voy a estudiar ao invés de aunque me pidas, no voy a estudiar. Há na primeira sentença, uma carga informacional muito maior que se apresenta inclusive no plano formal (na própria extensão do nexo concessivo). A diferença entre um conectivo concessivo simples e uma locução conjuncional como esta estudada no presente artigo, está justamente na maior carga de informação desta última que tende a amalgamar a noção de concessividade com outras noções semânticas, nesse caso, de intensidade.

Os resultados comprovam, portanto, a hipótese inicial desta pesquisa de que há diferenças semântico-pragmáticas entre as diferentes conjunções que assinalam a relação concessiva e que essa diferença se relaciona aos níveis e camadas propostos pela teoria da Gramática Discursivo-Funcional, uma vez que as concessivas intensivas do espanhol prefaciadas por por mucho que atuam especificamente na camada do Conteúdo Proposicional e na do Ato Discursivo.

\section{Referências}

BOSQUE, Ignacio; DEMONTE, Violeta (Org.). Gramática descriptiva de la lengua española: entre la oración y el discurso. Madrid: Espasaa-Calpe,1999.

CREVELS, Mily. Concession in spanish. In: HANNAY, Mike; BOLKESTEIN, Alide Machtelt. Functional grammar and verbal interaction. Amsterdam: J. B. Publishing, 1998. v. 44, p. 129-148. 
DANCYGIER, Barbara. Conditionals and predication: time knowledge and causation in conditional constructions. Cambridge: Cambridge University Press, 1998.

DANCYGIER, Barbara. Conditionals and Concessives. Papers and Studies in Contrastive Linguistics, n. 24, p. 111-121, 1988.

FLAMENCO GARCÍA, Luis. Las construcciones concesivas y adversativas. In: BOSQUE, Ignacio; DEMONTE, Violeta (Org.). Gramática descriptiva de la lengua española: entre la oración y el discurso. Madrid: Espasaa-Calpe,1999. v. 3, p. 3805- 3878.

GOUVÊA, Lúcia Helena Martins. Perspectivas argumentativas pela concessão em sentenças judiciais. 2002. Tese (Doutorado em Língua Portuguesa) - Faculdade de Letras da UFRJ, Universidade Federal do Rio de Janeiro, Rio de Janeiro.

HASPELMATH, Martin; KÖNIG, EKKEHARD. Concessive conditionals in the languages of Europe. In: AWERA, Johan van der. Adverbial clauses in the languages of Europe. Berlin: Mouton de Gruyter, 1998. p. 563-640.

HENGEVELD, Kees; MACKENZIE, Lachlan. Functional discourse grammar: a typologically based theory of language structure. Tradução de Marize Mattos Dall'Aglio Hattnher. Oxford: University Press, 2008.

HENGEVELD, Kees; MACKENZIE, Lachlan. Gramática discursivo-funcional. In: SOUZA, Edson Rosa Francisco de (Org.). Funcionalismo linguístico: novas tendências teóricas. Tradução de Marize Mattos Dall'Aglio-Hattnher. São Paulo: Contexto, 2012. p. 43-65.

KÖNIG, Ekkehard. Concessive clauses. In: ASHER, Ronald. (Ed.). The encyclopedia of language and linguistics. Oxford: Pergamon, 1994. v. 2, p. 679681.

MARGARIDO, Renata. Construções (coordenadas) adversativas e construções (subordinadas) adverbiais concessivas em português. pontos de contato e de contraste na língua em função. 2010. Dissertação (Mestrado em Letras) Universidade Presbiteriana Mackenzie, São Paulo.

MATTE BON, Francisco. Gramática comunicativa del Español. Madrid: Edelsa, 1995. Tomo 2.

NEVES, Maria Helena Moura. Gramática de usos do português. São Paulo: EDUNESP, 2000.

REAL ACADEMIA ESPAÑOLA. Nueva gramática de la Lengua Española. Madrid: Espasa Libros, 2010. 
RODRIGUES, Angela Cecília de Souza; CAMPOS, Odette Gertrudes Luiza Altmann de Souza; GALEMBECK, Paulo de Tarso. Correlação modo-temporal nas construções complexas: concessivas. In: NEVES, Maria Helena Moura (Org.). Gramática do português falado. 2. ed. Campinas: Ed. da Unicamp, 1999. v. 7, p. 653-672.

ROSÁRIO, Ivo da Costa. Construções concessivas intensivas. Confluência, Rio de Janeiro, v. 1, n. 46, p. 201-220, 2014.

SWEETSER, Eve. From Etymology to Pragmatics: Metaphorical and Cultural Aspects of Semantic Structure. Cambridge: Cambridge University Press, 1990. (Cambridge Studies in Linguistics, 54). 